
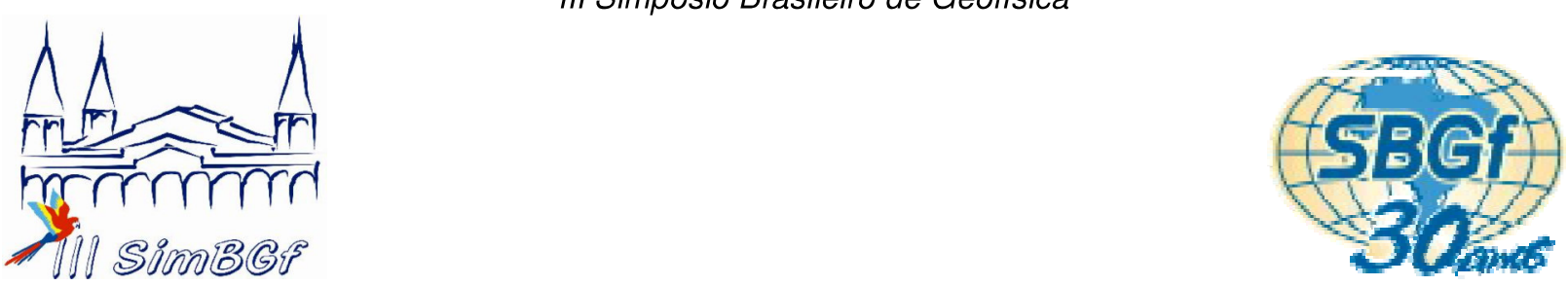

\title{
Estudo da estrutura da crosta da região norte do Brasil utilizando a Função do Receptor
}

Marina M. Dalla Costa ${ }^{1}$, George Sand França ${ }^{1}{ }^{2}$,Cristiano Naibert Chimpliganond ${ }^{1} 1$ - Observatório Sismológico de Brasília, Instituto de Geociências, UnB. 2 - Laboratório de Estudos da Litosfera, Instituto de Geociências, UnB

Este texto foi preparado para a apresentação no III Simpósio Brasileiro de Geofísica, Belém, 26 a 28 de novembro de 2008. Seu conteúdo foi revisado pelo Comitê Técnico do III SimBGt, mas não necessariamente representa a opinião da SBGf ou de seus associados. E proibida a reprodução total ou parcial deste material para propósitos comerciais sem prévia autorização da SBGt.

\section{Resumo}

A espessura crustal e razão $\mathrm{Vp} / \mathrm{Vs}$ para a região norte do país foram estimadas utilizando a metodologia da Função do Receptor a partir de dados obtidos em três estações banda-larga: TUCB, BALB e SAMB localizadas, respectivamente, nos estados do Pará, Amazonas e Rondônia. Aliou-se ao cálculo da Função do Receptor o procedimento HK-stacking, visando aumentar a acurácia dos resultados obtidos para tais parâmetros. Por fim, os resultados foram comparados com outros obtidos previamente em estações próximas às supracitadas. Nossa estimativa mostra valores menores em direção noroeste com razão $\mathrm{Vp} / \mathrm{Vs}$ variando de 1,66 a 1,85. A espessura crustal apresenta valores entre 41 a $47 \mathrm{~km}$.

Introdução

A região norte do Brasil possui deficiência de informações relativas à espessura crustal (profundidade da Moho) e Razão de Poisson (Vp/Vs). Tais informações são de grande importância para a caracterização da área, além de auxiliarem na confecção de modelos para a região. Utilizando a metodologia da Função do Receptor para os sismogramas referentes a telessismos, registrados em três estações triaxiais de banda larga, Samuel (SAMB), Tucuruí (TUCB) e Balbina (BALB), localizadas, respectivamente, nos estados de Rondônia, Pará e Amazonas, visa-se a obtenção de tais parâmetros (Figura 1).

As estações estudadas encontram-se sobre o Cráton Amazonas (SAMB e TUCB) e a Bacia do Amazonas (BALB). O Cráton Amazonas representa uma das maiores e menos conhecidas áreas pré-cambrianas do mundo. No Brasil, possui aproximadamente 4.400 .000 $\mathrm{km}^{2}$ e é limitado a leste, sul e sudeste por rochas geradas durante o Ciclo Orogênico Brasiliano. É em relação às rochas geradas durante esse ciclo orogênico que 0 conceito de cráton é aplicado, representando a área estabilizada em tempos pré-brasilianos (<850 Ma?). O cráton é coberto por diversas bacias fanerozóicas a nordeste (Maranhão), sul (Xingu e Alto Tapajós), sudoeste (Parecis), oeste (Solimões), norte (Tacutu) e centro (Amazonas) (Santos, 2003).

As rochas sedimentares da Bacia do Amazonas, que possui $515.000 \mathrm{~km}^{2}$ de área estão em onlap sobre as rochas pré-cambrianas dos escudos das Guianas a norte e Brasil Central a sul. Seu limite ocidental é com a Bacia do Solimões (Alto de Purus) e o oriental, com o rifte mesozóico de Marajó, é a ombreira do rifte, denominada de "Arco de Gurupá". A espessura total das rochas sedimentares que a preenchem atinge $5 \mathrm{~km}$ (da Silva et al., 2003).

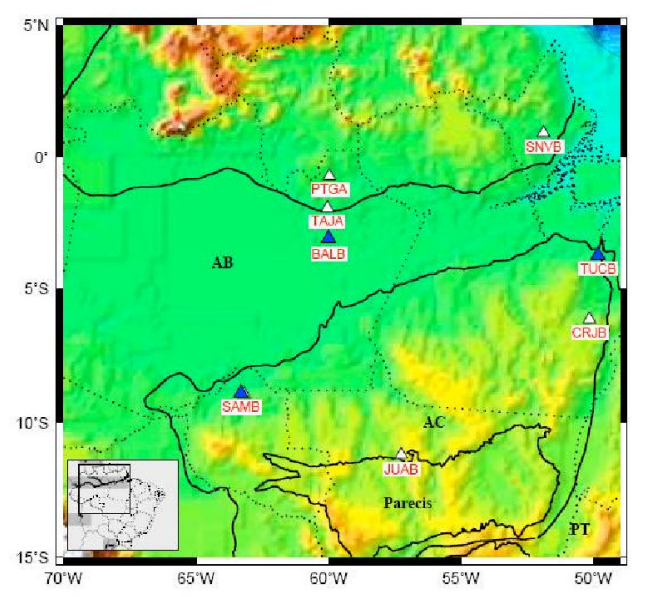

Figura 1 - Mapa das estações de Banda Larga e os limites do Cráton Amazonas. Triângulos azuis indicam a localização das estações utilizadas nesse estudo; Triângulos brancos = Estações com resultados já obtidos anteriormente. Linha contínua define os limites do cráton e linha pontilhada indica os limites dos estados. $A B=$ Bacia do Amazonas, $A C=$ Cráton Amazonas, Parecis = Bacia dos Parecis e PT= Província Tocantins. JUAB (França et al. 2005), SNVB e CRJB (Lloyd et al. 2007), PTGA (Crotwell \& Owens, 2005) e TAJA (Krüger et al. 2004). 


\section{Metodologia}

A deconvolução da componente radial pela vertical é denominada Função do Receptor (FR) (Langston, 1979, Ammon, 1990, 1991). A forma de onda da função do receptor é a resposta das heterogeneidades do interior da Terra sob cada estação (p.e. Descontinuidade de Moho), de forma que toda a energia da onda $P$ é somada ao pico principal, denominada de $P$ direta, e seguida por picos menores, que são fases convertidas e reverberadas na descontinuidade. A Figura 2 mostra um esquema da FR radial para um modelo com apenas uma descontinuidade de velocidade.

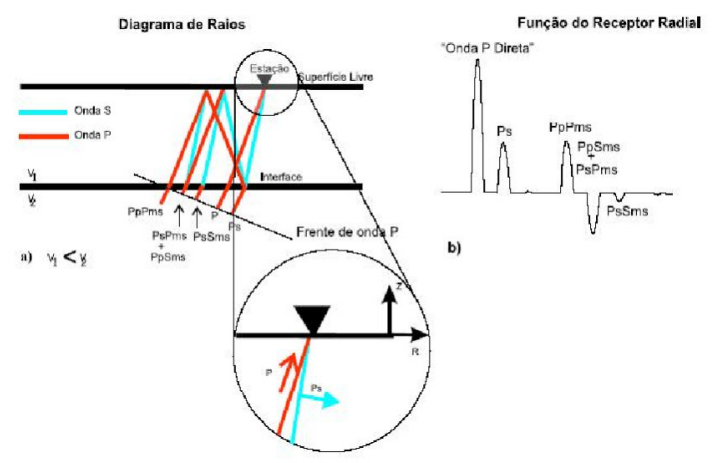

Figura 2 - Esquema da Função do Receptor obtida para modelo com uma descontinuidade

As diferenças temporais entre as chegadas das fases (p.e.: Ps e P; PpPms e Ps - Figura 2) são usadas na estimativa da espessura crustal $(H)$ e da razão de velocidades (Vp/Vs), utilizando as equações 1 e 2 (Zandt et al., 1995)

$$
\begin{gathered}
\frac{V_{P}}{V_{S}}=\sqrt{\left(1-p^{2} V_{P}\left[\left(\begin{array}{c}
\Delta_{P s} \\
\Delta_{P p P m s}
\end{array}\right)+1\right]^{2}+p^{2} V_{P}^{2}\right.} \\
H=\frac{\Delta_{P s}}{\sqrt{V_{S}^{-2}-p^{2}}-\sqrt{\bar{V}_{P}^{-2}-p^{2}}}
\end{gathered}
$$

Em que $\Delta_{P_{s}}$ é a diferença temporal entre as chegadas Ps e $\mathrm{P}$ direta, $\Delta_{\mathrm{PpPms}}$ é a diferença temporal entre as chegadas PpPms e Ps, p é parâmetro de raio, $V_{p}$ é velocidade da onda $P$ e $V_{S}$ é a velocidade da onda $S$.

\section{Análise de Dados e Resultados}

As FRs foram calculadas usando o filtro gaussiano [exp($\left.\omega^{2} / 4 \alpha^{2}\right)$ ], com parâmetro $\alpha$ igual a 3 , o que representa um filtro passa baixa com freqüência de corte igual a $1,5 \mathrm{~Hz}$. Para cada traço, o melhor valor de nível de água foi escolhido entre 0,01 e 0,001. A janela da FR difere para cada evento, buscando-se a duração que apresente a maior razão pré-sinal-ruído. As FRs foram calculadas usando as rotinas fornecidas por C. J. Ammon.
Foram selecionados 105 telessismos com magnitudes maiores que 4,5 e distância epicentral entre 18 e $99^{\circ}$ (Figura 3). As FRs foram empilhadas de acordo com os azimutes e as vagarosidades, conforme evidenciado na Figura 4, na qual o número de traços empilhados não excedeu de cinco. A componente transversal indica o grau de variabilidade lateral (para estruturas puramente homogêneas, a componente transversal seria zero).

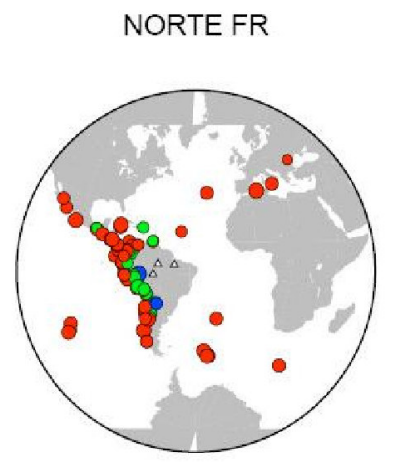

Figura 3 - Localização dos epicentros dos 105 telessismos utilizados para calcular a FR. Círculos representam os epicentros utilizados.

As FRs mostraram a fase Ps clara para a maioria dos traços. Entretanto, a visibilidade da fase PpPms é dificultada pela baixa razão sinal-ruído no final do traço. Após essa seleção aplicamos as equações 1 e 2 através do procedimento HK-stacking de Zhu \& Kanamori (2000). Essa técnica usa a correção moveout relativa às chegadas secundárias, geradas em uma descontinuidade sísmica abaixo da estação, para inferir a profundidade e a razão Vp/Vs acima da descontinuidade (Figura 5). De acordo com a equação, a única informação necessária é a Vp. Para as primeiras estimativas usamos a velocidade da onda de $6,4 \mathrm{~km} / \mathrm{s}$, que é próximo do valor médio para crosta de acordo com Mooney et al. (1998).

A Tabela 1 mostra as razões com suas respectivas qualidades para $a=3$. A partir da razão e da espessura crustal para cada estação, corrigimos por NMO as FRs em relação à fase Ps (Figura 5) obtendo assim as espessuras descritas na Tabela 1.

Tabela 1- Valores de espessura crustal - Moho $(\mathrm{km}) \mathrm{com}$ função do receptor usando $V p$ igual $6,4 \mathrm{~km} / \mathrm{s}$ para as estações.

\begin{tabular}{|c|c|c|}
\hline Estação & $\begin{array}{c}\text { Moho_HK } \\
(\mathrm{km})\end{array}$ & $\mathrm{Vp} / \mathrm{Vs}$ \\
\hline TUCB & $46,0 \pm 3,5$ & $1,66 \pm 0,08$ \\
\hline SAMB & $43,2 \pm 2,7$ & $1,81 \pm 0,05$ \\
\hline BALB & $27,6 \pm 6,8$ & $1,77 \pm 0,06$ \\
\hline
\end{tabular}




\section{BALB}

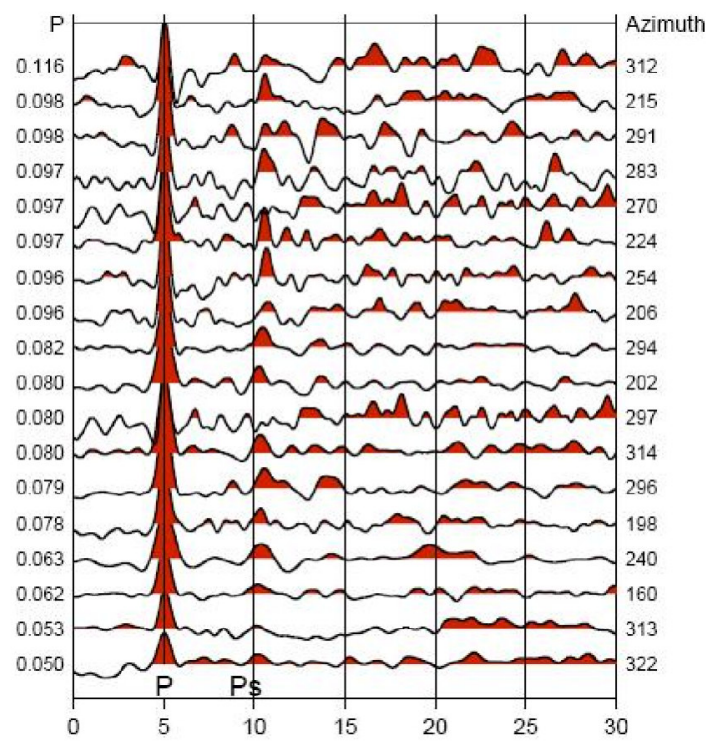

Figura 4 - Funções dos receptores ordenadas de acordo com a vagorisidade.

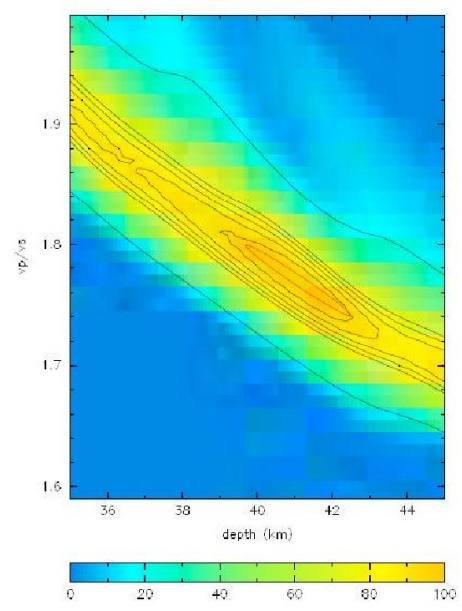

Figura 5 - Análise HK-stacking analises para estação $B A L B$, usamos a Vp igual a $6,4 \mathrm{~km} / \mathrm{s}$.

\section{Discussão e Conclusões}

Os resultados preliminares mostram consistência com valores já obtidos para estações na área de estudo (Lloyd et al. 2007; Krüger et al. 2002, Crotwell \& Owens, 2005), (Figura 6). Esses resultados mostram que a crosta é mais fina na direção norte da área estuda, no entanto a ausência de mais estações na parte superior do Cráton não permite uma discussão sobre um possível afinamento crustal, não evidenciando se ocorre em direção norte ou apenas sob a bacia intracratônica. Os valores de razão $\mathrm{Vp} / \mathrm{Vs}$ são menores na parte leste, o que sugere uma crosta inferior diferenciada da parte central do Cráton Amazonas. Cordani \& Sato (1999), indicam a ocorrência de aglutinação de arcos magmáticos juvenis durante a orogênese proterozóica podendo, portanto, correlacionar os valores $\mathrm{Vp} / \mathrm{Vs} \mathrm{da}$ parte central do cráton prováveis indicativos de crosta máfica (Musacchio et al., 1997).

Os dados apresentam uma razão sinal-ruído maior do que outras regiões, podendo ser reflexo de problemas nos procedimentos de instalação das estações, que podem estar sofrendo com a variação temporal. No entanto, foi possível visualizar as fases características da FR. As FRs tangencias para as estações SAMB e BALB apresentaram uma razão sinal-ruído para fase $P$ direta maior, provavelmente devido à influência do espalhamento por prováveis variações laterais, e devido à camada sedimentar.

Para possibilitar discussões mais concretas, os próximos passos que serão tomados consistem em realizar correlação com a gravimetria e ondas superficiais, na tentativa de inversão conjunta com FR.

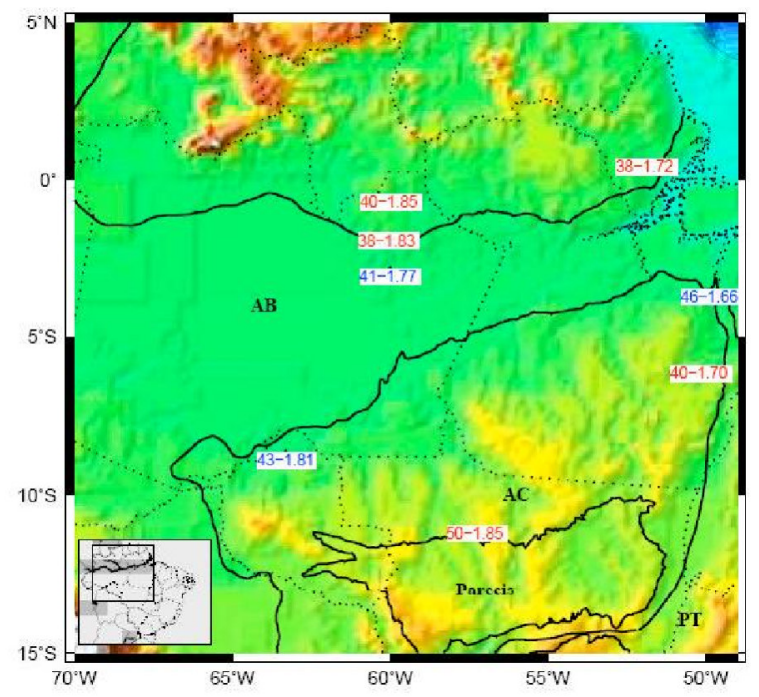

Figura 6 - Mapa de espessuras crustais e razão $\mathrm{Vp} / \mathrm{Vs}$. Em azul, valores obtidos nesse trabalho e em vermelhos, valores obtidos por Lloyd et al. 2007; Krüger et al. 2002, Crotwell \& Owens, 2005.

\section{Agradecimentos}

Os autores agradecem 0 apoio da FINATEC Edital 02/2007, aos técnicos responsáveis pela manutenção das estações utilizadas, a Diogo Farrapo pelo auxílio na conversão de dados, ao IRIS pelos dados da estação RCBR e a Charles Ammon e Jordi Juliá pelos programas. Os mapas foram feitos usando o GMT. GSF agradece a CNPq pelo apoio, através da bolsa $\mathrm{PQ}$ (processo 302398/2007-4)

\section{Referências}

Ammon, C.J., 1991. The isolation effects from teleseismic P-waveforms. Bull. Seism. Soc. Am. 81, 2504-251 
Ammom, C. J., G. E. Randall \& G. Zandt, 1990. On the nonuniqueness of receiver functions inversions, $J$. Geophys. Res., 95, 15303-15318.

Cordani, U.G., Sato, K. 1999. Crustal evolution of the South American Platform, based on $\mathrm{Nd}$ isotopic systematics on granitoid rocks, Episodes, Vol. 22, no. 3, p.167-173.

Crotwell H.P. and Owens T.J. 2005. Automated receiver function processing. Seismological Research Letters, 76:702-708,.

Da Silva, A. J. P., Lopes, R. C., Vasconcelos, A. M., Bahia, R. B. C. Bacias Sedimentares Paleozóicas e Meso-Cenozóicas Interiores. In: Bizzi, L. A., Schobbenhaus, C., Vidotti, R. M., Gonçalves, J. H. (eds.). Geologia, Tectônica e Recursos Minerais do Brasil. CPRM, Brasília, 2003, 55-85.

Langston, C.A., 1979. Structure under Mount Rainier, Washington, inferred from teleseismic body waves. J. Geophys. Res. 85, 4749-4762.

Lloyd, S., Van der Lee, S., França, G. S., Assumpção, M., Feng, M., 2007. New Moho map for South America from receiver functions and surface waves, Eos Trans. AGU, 88(23), Jt. Assem. Suppl., Abstrac S44A-04

Krüger F., Scherbaum F., Rosa J.W.C., Kind R., Zetsche F. and Hohne J., 2002. Crustal and upper mantle structure in the Amazon region (Brazil) determined with broadband mobile stations, J. Geophys. Res. 107 (B10), p. 2265

França, G. S.; Bianchi, M.; Assumpção, M.; Chimpliganond C. N.; Barbosa M. F. N.; Barros, L. V., 2005. Crustal structure of the North and Northest Brazil derived from receiver functions. In: IASPEI General Assembley, 2005, Chile. IASPEI General Assembley.

Cordani, U.G., Sato, K. 1999. Crustal evolution of the

South American Platform, based on $\mathrm{Nd}$ isotopic systematics on granitoid rocks, Episodes, Vol. 22, no. 3, p.167-173.

Santos, J. O. S. Geotectônica dos Escudos das Guianas e Brasil-Central. In: Bizzi, L. A., Schobbenhaus, C., Vidotti, R. M., Gonçalves, J. H. (eds.). Geologia, Tectônica e Recursos Minerais do Brasil. CPRM, Brasília, 2003, 169-226.

Zhu, L., and H. Kanamori, 2000. Moho depth variation in southernCalifornia from teleseismic receiver functions, $J$. Geophys. Res., 105 , 2969-2980. 